\title{
HLA class II alleles may influence susceptibility to adult dermatomyositis and polymyositis in a Han Chinese population
}

\author{
Xiang Gao ${ }^{1,2+}$, Lei $\mathrm{Han}^{2 \dagger}$, Lan Yuan ${ }^{3,4+}$, Yongchen Yang ${ }^{5}$, Guimei Gou ${ }^{5}$, Hengjuan Sun ${ }^{5}$, Ling Lu ${ }^{2 *}$ \\ and Liming $\mathrm{BaO}^{3,4,6^{*}}$
}

\begin{abstract}
Background: Polymyositis (PM) and dermatomyositis (DM) are idiopathic inflammatory myopathies. Genetic variability in human leukocyte antigen (HLA) genes plays an important role in the pathogenesis of PM and DM. However, few studies on the subject in Chinese populations have been reported thus far.

Methods: We studied the influence of HLA polymorphisms on DM and PM susceptibility by analyzing HLA-DRB1, HLA-DQA1, and HLA-DQB1 alleles in 71 adult DM patients, 20 adult PM patients, and 113 controls in a Han Chinese population.

Results: A positive association was found between HLA-DQA1*0104 and DM ( $p=0.01$; corrected $p\left(p_{\text {corr }}\right)$ NS; odds ratio $(\mathrm{OR})=2.58 ; 95 \%$ confidence interval $(\mathrm{Cl}): 1.18-5.64)$, while an inverse correlation was noted between HLA-DQB1*0303 and myositis patients with interstitial lung inflammation $\left(p=0.01 ; p_{\text {corr }} N S ; O R=0.25 ; 95 \% \mathrm{Cl}\right.$ : $0.07-0.73)$. A positive relationship was also observed between $H L A-D R B 1 * 07$ and $\mathrm{DM}\left(p=0.01 ; p_{\text {corr }} \mathrm{NS} ; \mathrm{OR}=2.26\right.$; $95 \%$ Cl: $1.12-4.59)$, while HLA-DRB ${ }^{*} 03$ seems to be protective against DM ( $p=0.01 ; p_{\text {corr }} N S ; O R=0.26 ; 95 \% \mathrm{Cl}$ : 0.06-0.81). The lung complication was closely associated with HLA-DRB1*04 ( $p=0.01 ; p_{\text {corr }} N S ; O R=2.82 ; 95 \% \mathrm{Cl}$ : $1.15-6.76)$ and $H L A-D R B 1^{*} 12$ ( $\left.p=0.02 ; p_{\text {corr }} N S ; O R=2.52 ; 95 \% \mathrm{Cl}: 1.02-6.07\right)$. The frequency of HLA-DRB1*07 was significantly higher among myositis patients with dysphagia than among controls $\left(p=0.01 ; p_{\text {corr }} N S ; O R=4.78\right.$; 95\% Cl: 1.03-24.42). The putative haplotype $D R B 1 * 07-D Q A 1 * 01-D Q B 1 * 02$ was positively correlated with $D M(p=0.03$; $\left.p_{\text {corr }} N S ; O R=2.90 ; 95 \% \mathrm{Cl}: 1.02-8.93\right)$ and the lung complication ( $\left.p=0.02 ; p_{\text {corr }} N S ; O R=3.45 ; 95 \% \mathrm{Cl}: 1.04-11.58\right)$.
\end{abstract}

Conclusions: Our results demonstrate that HLA alleles may be involved in susceptibility to adult DM and PM in the Han Chinese population.

Keywords: Polymyositis, Dermatomyositis, HLA, Susceptibility, Chinese

\section{Background}

Polymyositis (PM) and dermatomyositis (DM) are idiopathic inflammatory myopathies (IIM), a group of autoimmune disorders characterized by inflammation present predominantly in muscle tissues. The chief clinical presentations include symmetric proximal muscle weakness,

\footnotetext{
*Correspondence: huashanlvling@sina.com; liming.bao@dartmouth.edu ${ }^{\dagger}$ Equal contributors

${ }^{2}$ Departments of Rheumatology and Occupational Medicine, Huashan Hospital of Fudan University, Shanghai, China

${ }^{3}$ Center for Clinical Molecular Medicine; Ministry of Education Key Laboratory of Child Development and Disorders, Key Laboratory of Pediatrics in Chongqing, Chongqing, China

Full list of author information is available at the end of the article
}

other organ involvement, and presence of autoantibodies [1]. Although the underlying pathogenesis for PM and DM remains unclear, evidence has suggested that, like many other autoimmune conditions, these disorders likely result from a combination of environmental exposure and genetic susceptibility [2]. Genetic variability in the human leukocyte antigen (HLA) genes is thought to play an important role in DM and PM pathogenesis [3,4]. This may be partly attributed to the influence of HLA molecules on T-cell receptor development, peripheral tolerance, and immune response to environmental agents. It has been established that geographic locations and ethnicities may affect susceptibility to autoimmune diseases $[5,6]$. The 
$H L A-D R B 1 * 0301$ and HLA-DQA1*0501 alleles have been reported as risk factors for myositis in Western populations [7,8], whereas DRB1*0803 may increase PM susceptibility among the Japanese population [9]. In studies of 52 DM and PM patients from Northern China, Han et al. reported positive associations between the $H L A-D R B 1 * 04$, $H L A-D R B 1 * 07$, and $H L A-D R B 1 * 12$ alleles and DM development [10]. They also observed that $H L A-D Q B 1 * 0401$ is a risk factor for DM and PM [11]. However, the sample sizes of these studies were small; therefore, the possible role of $H L A$ class II alleles in myopathies in Chinese patients requires further investigation.

To assess the effect of polymorphisms in $H L A-D R B 1$, $H L A-D Q A 1$, and HLA-DQB1 on DM and PM susceptibility, we conducted a study of 91 adult patients with DM or PM and 113 healthy controls in a Han Chinese population. Our results demonstrate that $H L A$ class II alleles may influence adult DM and PM susceptibility in the Han Chinese population.

\section{Methods \\ Study subjects}

Between August 2009 and March 2012, 71 and 20 patients were diagnosed with DM and PM, respectively, at the Huashan Hospital of Fudan University in Shanghai, China. The patients met probable or definite diagnosis of DM or PM according to the Bohan and Peter [12] criteria [12,13]. Lung lesions were examined by chest computed tomography, and a diagnosis of interstitial lung disease (ILD) or idiopathic interstitial pneumonitis was made by a pulmonologist. All patients were ethnic Han Chinese (25 males and 66 females, median age of $51 \pm 15.8$ years). One hundred and thirteen healthy Han Chinese subjects (36 males and 77 females, median age of $40.0 \pm 8.6$ years) with no history of autoimmune disease were enrolled in the study as controls. The study followed protocols set by the Declaration of Helsinki and was approved by the ethics committee of Huashan Hospital. All patients and controls provided written informed consent prior to the study.

\section{Experiments}

DNA was extracted from blood using the Qiagen DNA extraction kit (Qiagen; Hilden, Germany). Low- and highresolution typing of the $H L A-D R B 1, H L A-D Q A 1$, and $H L A-D Q B 1$ alleles were performed using the polymerase chain reaction (PCR)-sequence-specific primed (SSP) procedure described by Olerup et al. [14,15]. Serum was obtained from all patients for detection of myositisspecific antibodies (MSA; anti-Jo-1 autoantibodies) and myositis-associated antibodies (MAA; anti-Ro and anti-La autoantibodies). Autoantibodies were analyzed by an indirect immunofluorescence method using the kits from EUROIMMUN AG (Lubeck, Germany).

\section{Statistical analysis}

The allele, genotype, and haplotype frequencies of the $H L A$ loci were compared between the patients and controls using the Fisher exact test or chi-square test, as appropriate. Data were expressed as odds ratios (ORs) with 95\% confidence intervals (CIs). A $p$-value $\leq 0.05$ was considered statistically significant. In multiple comparisons, $p$-values were adjusted using the Bonferroni correction to give a corrected $p$-value $\left(p_{\text {corr }}\right) . A$ A $p$-value $\leq 0.05$ before correction for multiple comparisons was considered as possibly statistically significant. The Hardy-Weinberg equilibrium constant in the control group was confirmed using a chi-square test. Putative haplotypes were inferred from unphased genotype data using the Bayesian statistical method available in the PHASE program v2.1.1 [16]. Putative haplotypes with a frequency higher than $3 \%$ among the controls were selected for further comparisons between the patients and controls. Unless otherwise stated, Stata (version 7.0; Stata Corp.; College Station, TX, USA) statistical software was used to perform the statistical analyses.

\section{Results}

Of the 91 patients, 71 had been diagnosed with DM and 20 with PM (66 female and 25 male [2.64:1]). Although most of the patients were positive for antinuclear antibodies, few were positive for either MSA or MAA. The frequencies of MSA and MAA were higher in the PM group than in the DM group (10\% vs. $1.4 \%, p=0.06$ for MSA; $20 \%$ vs. $5.63 \%, p=0.05$ for MAA). As expected, cutaneous involvement such as rash or cuticular overgrowth was present only in DM patients. Approximately half of the patients had ILD, with a higher prevalence among patients with PM than those with DM $(76.5 \%$ vs. $37.7 \%, p=0.04)$. No significant differences in other clinical features were observed between the two groups (Table 1).

Genotyping analyses of the HLA-DQA1 and HLA$D Q B 1$ loci were performed to study the relationship between the HLA class II alleles and susceptibility to DM and PM. Because there are several lines of evidence to suggest that DM and PM may be distinct diseases with different genetic backgrounds [17], we analyzed the influence of the $H L A$ alleles on susceptibility to DM and PM individually rather than analyzing the combined $\mathrm{DM} / \mathrm{PM}$ group (Table 2). Compared with the controls, the frequency of $H L A-D Q A 1 * 0104$ was significantly higher in the DM group than in the PM group (16.42\% vs. $8.18 \%$, $p=0.01, p_{\text {corr }} \mathrm{NS} ; \mathrm{OR}=2.58$; 95\% CI: $\left.1.18-5.74\right)$, implying a possible positive correlation between $H L A-D Q A 1^{*} 0104$ and the risk of DM. Of the $H L A-D Q B 1$ alleles analyzed, only the $H L A-D Q B 1 * 0303$ frequency was lower in patients with ILD than in the controls $(6.76 \%$ vs. $19.03 \%, p=0.01$, $p_{\text {corr }} \mathrm{NS}$; OR $\left.=0.25 ; 95 \% \mathrm{CI}: 0.07-0.73\right)$, implying that 
Table 1 Clinical features of patients with DM and PM

\begin{tabular}{lccc}
\hline & $\begin{array}{c}\text { DM n (\%) } \\
(\mathbf{N}=\mathbf{7 1})\end{array}$ & $\begin{array}{c}\text { PM } \mathbf{n}(\%) \\
(\mathbf{N}=\mathbf{2 0})\end{array}$ & $\begin{array}{c}\boldsymbol{p} \text { (DM } \\
\text { vs. PM) }\end{array}$ \\
\hline Serologic group & & & \\
MSA (anti-Jo-1) & $1(1.4)$ & $2(10)$ & 0.06 \\
MAA (SSA, SSB or Scl) & $4(5.63)$ & $4(20)$ & 0.05 \\
Clinical presentations & & & \\
Fever & $4(5.6)$ & $1(5)$ & 0.92 \\
Raynaud's disease & 0.00 & $1(5)$ & 0.06 \\
Arthritis & $1(1.4)$ & 0.00 & 0.59 \\
Interstitial lung disease & $26^{1}(37.7)$ & $13^{2}(76.5)$ & 0.04 \\
Palpitations & $1(1.4)$ & 0.00 & 0.59 \\
Dysphagia & $10(14.1)$ & $4(20)$ & 0.51 \\
V-sign & $26(36.6)$ & 0.00 & n/a \\
Gottron papules & $24(33.8)$ & 0.00 & $n / a$ \\
Periorbital edematous rash & $11(15.5)$ & 0.00 & n/a \\
Shawl sign & $13(18.3)$ & 0.00 & n/a \\
Cuticular overgrowth & $3(4.2)$ & 0.00 & n/a \\
\hline
\end{tabular}

MSA: myositosis-specific autoantiboides; MAA: myositosis associated autoantibodies;

${ }^{1} 69$ DM patients evaluated; ${ }^{2} 17$ PM patients evaluated; n/a: not applicable.

patients with this allele are less likely to develop the lung complication. This was further confirmed by the fact that the $H L A-D Q B 1^{*} 0303$ frequency was lower among those who developed ILD $(p<0.01$; OR $=0.19 ; 95 \%$ CI: $0.038-$ $0.37)$ than those who did not develop ILD. HLA-DRB1 typing analysis showed that compared to controls, DM patients had a considerably lower prevalence of $H L A$ $D R B 1^{*} 03$ (3.08\% vs. $11.27 \%, p=0.01, p_{\text {corr }} \mathrm{NS}$; OR $=0.26$; 95\% CI: $0.06-0.81)$ and a higher frequency of HLA$D R B 1^{*} 07$ (20.77\% vs. $13.24 \%, p=0.01$, $p_{\text {corr }} \mathrm{NS}$, OR $=2.26$, 95\% CI, 1.12-4.59). Both HLA-DRB1:04 and HLA$D R B 1 * 12$ alleles are likely linked to the lung disease $(p=$ $0.01, p_{\text {corr }} \mathrm{NS} ; \mathrm{OR}=2.82$; $95 \% \mathrm{CI}: 1.15-6.76$ and $p=0.02$, $p_{\text {corr }} \mathrm{NS} ; \mathrm{OR}=2.52 ; 95 \% \mathrm{CI}: 1.02-6.07$, respectively). A similar effect of $H L A-D R B 1 * 04$ on ILD development was also observed when the allele frequencies between patients with and without the lung complication were compared $(p=0.026$; OR $=3.32 ; 95 \%$ CI: $1.22-9.08)$. Comparison of HLA-DRB1*12 allele frequencies between myositis patients with and without ILD showed a similar trend of being higher among those with ILD than among those without, although the difference between the two groups was not statistically significant $(p=0.35 ; \mathrm{OR}=1.59$; 95\% CI: $0.63-4.00$ ). This is likely attributable to the small numbers in the groups examined. Moreover, the $H L A-D R B 1 * 07$ allele showed a possible influence on the development of esophageal/muscle complications $(30.00 \%$ vs. $13.24 \%, p=0.01, p_{\text {corr }} \mathrm{NS}$; OR $=4.78$; $95 \% \mathrm{CI}$ : $1.03-$ 24.42). A similar trend for a higher $H L A-D R B 1 * 07$ allele frequency was also noted among patients who had dysphagia as compared to those who did not $(p=0.057$; $\mathrm{OR}=3.55$; 95\% CI: 0.91-13.82).

We then examined the association between putative haplotypes involving the DRB1-DQA1-DQB1 loci and susceptibility to DM, PM, lung, and esophageal complications. In this analysis, only the putative haplotypes present in at least 3\% of the controls were selected for further study. Of the 12 putative haplotypes selected, the frequency of $D R B 1 * 07-D Q A 1 * 01-D Q B 1 * 02$ was higher in the DM group $\left(p=0.03, p_{\text {corr }} \mathrm{NS}\right.$; OR $=2.90 ; 95 \% \mathrm{CI}$ : $1.02-8.93)$ and in patients with ILD $\left(p=0.02, p_{\text {corr }}\right.$ NS; $\mathrm{OR}=3.45$; $95 \%$ CI: $1.04-11.58$ ) than in the controls, indicating that this putative haplotype might increase the risk of DM and the lung complication (Table 3). A further comparison of the DRB1*07-DQA1*01-DQB1*02 frequency in patients who developed dysphagia with those who did not showed a trend for a higher frequency of this haplotype among patients with dysphagia, although the difference between the groups was not statistically significant $(p=0.23$; OR $=2.27$; 95\% CI: $0.68-7.72)$. Again, we consider that this result is likely due to the small sample sizes in both groups.

\section{Discussion}

There are differences in the clinical features of DM and PM between our cohort of Han Chinese patients and Western patients $[1,18]$. There are more DM cases in our cohort and among Mesoamerican patients, whereas PM is the major subtype among Caucasian patients [19]. Compared to Caucasian patients, our cohort had a higher prevalence of the lung complication [20]. The frequencies of dysphagia were comparable between our cohort and those reported in the West $[1,21]$. Approximately $30-40 \%$ of Caucasian and African American IIM patients are positive for MSA/MAA autoantibodies [19,22]. Although the proportion of patients who were positive for autoantibodies was relatively low in our cohort, it is nonetheless comparable to findings from other studies in Chinese patients [23,24].

There is a growing body of evidence to suggest that differences in the impact of $H L A$ class II alleles on the susceptibility to DM and PM may exist among different ethnic groups and geographic locations [19,20,25-27]. It has been well documented that HLA class II alleles that form the 8.1 ancestral haplotype (8.1 AH), DRB1*03$D Q A 1 * 05-D Q B 1 * 02$, are closely linked to DM and PM in Western populations $[4,7,28]$. Previous studies suggest that HLA-DQA1"0501 and HLA-DRB1*0301 may be risk factors for PM, whereas HLA-DQA1*0201 and HLA$D R B 1 * 0401$ confer protection against the disease in Caucasians [4,28-30]. Moreover, HLA-DRB1*07 has been reported to protect against PM and IIM in Caucasians and African Americans [4,22,28]. In their study of African American patients with IIM, O'Hanlon et al. [22] 
Table 2 HLA-DQA1, HLA-DQB1, and HLA-DRB1 allele frequencies in PM and DM patients and controls

\begin{tabular}{|c|c|c|c|c|c|c|c|c|c|}
\hline \multirow{2}{*}{$\begin{array}{l}\text { Loci// } \\
\text { alleles }\end{array}$} & \multirow{2}{*}{$\begin{array}{c}\text { DM } \\
\text { n (\%) }\end{array}$} & \multirow{2}{*}{$\begin{array}{c}\text { PM } \\
\text { n (\%) }\end{array}$} & \multirow{2}{*}{$\begin{array}{c}\text { Myositis } \\
\text { with ILD } \\
\text { n (\%) }\end{array}$} & \multirow{2}{*}{$\begin{array}{c}\text { Myositis with } \\
\text { dysphagia } \\
\text { n (\%) }\end{array}$} & \multirow{2}{*}{$\begin{array}{l}\text { Control } \\
\text { n (\%) }\end{array}$} & \multicolumn{4}{|c|}{ Control vs. indicated patients ( $p$; OR $(95 \% \mathrm{CI}))$} \\
\hline & & & & & & DM & PM & $\begin{array}{l}\text { Myositis } \\
\text { with ILD }\end{array}$ & $\begin{array}{c}\text { Myositis with } \\
\text { dysphagia }\end{array}$ \\
\hline HLA-DRB1 & $N=65$ & $N=19$ & $N=37$ & $N=10$ & $N=113$ & & & & \\
\hline${ }^{*} 01$ & $1(0.77)$ & $0(0.00)$ & $1(1.35)$ & $0(0.00)$ & $5(2.45)$ & $n / s$ & $\mathrm{n} / \mathrm{a}$ & $n / s$ & $\mathrm{n} / \mathrm{a}$ \\
\hline \multirow[t]{2}{*}{ *03 } & $4(3.08)$ & $4(10.53)$ & $4(5.41)$ & $1(5.00)$ & $23(11.27)$ & $0.01^{1} ; 0.26$ & $\mathrm{n} / \mathrm{s}$ & $n / s$ & $n / s$ \\
\hline & & & & & & $(0.06-0.81)$ & & & \\
\hline \multirow[t]{2}{*}{${ }^{*} 04$} & $17(13.08)$ & $6(15.79)$ & $15(20.27)$ & $2(10.00)$ & $22(10.78)$ & $n / s$ & $\mathrm{n} / \mathrm{s}$ & $0.01^{1} ; 2.82$ & $n / s$ \\
\hline & & & & & & & & $(1.15-6.76)$ & \\
\hline \multirow[t]{2}{*}{$* 07$} & $27(20.77)$ & $1(2.63)$ & $14(18.92)$ & $6(30.00)$ & $27(13.24)$ & $0.01^{1} ; 2.26$ & $\mathrm{n} / \mathrm{s}$ & $n / s$ & $0.01^{1} ; 4.78$ \\
\hline & & & & & & $(1.12-4.59)$ & & & $(1.03-24.42)$ \\
\hline${ }^{*} 08$ & $13(10.00)$ & $4(10.53)$ & $7(9.46)$ & $2(10.00)$ & $17(8.33)$ & $\mathrm{n} / \mathrm{s}$ & $\mathrm{n} / \mathrm{s}$ & $\mathrm{n} / \mathrm{s}$ & $\mathrm{n} / \mathrm{s}$ \\
\hline *09 & $20(15.38)$ & $2(5.26)$ & $3(4.05)$ & $3(15.00)$ & $26(12.75)$ & $n / s$ & $\mathrm{n} / \mathrm{s}$ & $n / s$ & $n / s$ \\
\hline$* 10$ & $2(1.54)$ & $1(2.63)$ & $2(2.70)$ & $0(0.00)$ & $3(1.47)$ & $n / s$ & $\mathrm{n} / \mathrm{s}$ & $n / s$ & $\mathrm{n} / \mathrm{a}$ \\
\hline *11 & $3(2.31)$ & $3(7.89)$ & $2(2.70)$ & $0(0.00)$ & $9(4.41)$ & $n / s$ & $\mathrm{n} / \mathrm{s}$ & $n / s$ & $\mathrm{n} / \mathrm{a}$ \\
\hline \multirow[t]{2}{*}{$* 12$} & $20(15.38)$ & $7(18.42)$ & 14 (18.92) & $1(5.00)$ & $22(10.78)$ & $n / s$ & $n / s$ & $0.02^{1} ; 2.52$ & $n / s$ \\
\hline & & & & & & & & $(1.02-6.07)$ & \\
\hline$* 13$ & $7(5.38)$ & $1(2.63)$ & $2(2.70)$ & $1(5.00)$ & $8(3.92)$ & $n / s$ & $\mathrm{n} / \mathrm{s}$ & $n / s$ & $n / s$ \\
\hline$* 14$ & $2(1.54)$ & $3(7.89)$ & $1(1.35)$ & $2(10.00)$ & $9(4.41)$ & $n / s$ & $\mathrm{n} / \mathrm{s}$ & $n / s$ & $n / s$ \\
\hline *15 & $10(7.69)$ & $4(10.53)$ & $7(9.46)$ & $1(5.00)$ & $29(14.22)$ & $n / s$ & $\mathrm{n} / \mathrm{s}$ & $n / s$ & $n / s$ \\
\hline$* 16$ & $4(3.08)$ & $2(5.26)$ & $2(2.70)$ & $1(5.00)$ & $4(1.96)$ & $n / s$ & $\mathrm{n} / \mathrm{s}$ & $n / s$ & $n / s$ \\
\hline HLA-DQA1 & $N=67$ & $N=20$ & $N=39$ & $N=12$ & $N=110$ & & & & \\
\hline${ }^{*} 0101$ & $9(6.72)$ & $0(0.00)$ & $5(6.41)$ & $1(4.17)$ & $11(5.00)$ & $\mathrm{n} / \mathrm{s}$ & $\mathrm{n} / \mathrm{a}$ & $\mathrm{n} / \mathrm{s}$ & $\mathrm{n} / \mathrm{s}$ \\
\hline${ }^{*} 0102$ & $18(13.43)$ & $10(25.00)$ & $16(20.51)$ & $4(16.67)$ & $44(20.00)$ & $n / s$ & $\mathrm{n} / \mathrm{s}$ & $n / s$ & $\mathrm{n} / \mathrm{s}$ \\
\hline${ }^{*} 0103$ & $26(19.40)$ & $6(15.00)$ & $10(12.82)$ & $6(25.00)$ & $28(12.73)$ & $\mathrm{n} / \mathrm{s}$ & $\mathrm{n} / \mathrm{s}$ & $\mathrm{n} / \mathrm{s}$ & $n / s$ \\
\hline \multirow[t]{2}{*}{ *0104 } & $22(16.42)$ & $4(10.00)$ & $11(14.10)$ & $4(16.67)$ & $18(8.18)$ & $0.01^{1} ; 2.58$ & $\mathrm{n} / \mathrm{s}$ & $\mathrm{n} / \mathrm{s}$ & $n / s$ \\
\hline & & & & & & $1.18-5.64)$ & & & \\
\hline${ }^{*} 0201$ & $1(0.75)$ & $2(5.00)$ & $1(1.28)$ & $0(0.00)$ & $1(0.45)$ & $n / s$ & $\mathrm{n} / \mathrm{s}$ & $\mathrm{n} / \mathrm{s}$ & $\mathrm{n} / \mathrm{a}$ \\
\hline${ }^{*} 0301$ & $44(32.84)$ & $9(22.50)$ & $26(33.33)$ & $9(37.50)$ & 85 (38.64) & $n / s$ & $\mathrm{n} / \mathrm{s}$ & $\mathrm{n} / \mathrm{s}$ & $n / s$ \\
\hline${ }^{*} 0302$ & $1(0.75)$ & $0(0.00)$ & $0(0.00)$ & $0(0.00)$ & $1(0.45)$ & $n / s$ & $\mathrm{n} / \mathrm{a}$ & $\mathrm{n} / \mathrm{a}$ & $\mathrm{n} / \mathrm{a}$ \\
\hline${ }^{*} 0401$ & $1(0.75)$ & $2(5.00)$ & $2(2.56)$ & $0(0.00)$ & $3(1.36)$ & $n / s$ & $\mathrm{n} / \mathrm{s}$ & $n / s$ & $\mathrm{n} / \mathrm{a}$ \\
\hline${ }^{*} 0501$ & $11(8.21)$ & $6(15.00)$ & $6(7.69)$ & $0(0.00)$ & $28(12.73)$ & $n / s$ & $n / s$ & $n / s$ & $\mathrm{n} / \mathrm{a}$ \\
\hline${ }^{*} 0507$ & $1(0.75)$ & $0(0.00)$ & $0(0.00)$ & $0(0.00)$ & $0(0.00)$ & $\mathrm{n} / \mathrm{a}$ & $\mathrm{n} / \mathrm{a}$ & $\mathrm{n} / \mathrm{a}$ & $\mathrm{n} / \mathrm{a}$ \\
\hline${ }^{*} 0601$ & $0(0.00)$ & $1(2.50)$ & $1(1.28)$ & $0(0.00)$ & $1(0.45)$ & $n / a$ & $n / s$ & & \\
\hline$H L A-D Q B 1$ & $N=67$ & $N=17$ & $N=37$ & $N=10$ & $N=113$ & & & & \\
\hline${ }^{*} 0201$ & $31(23.48)$ & $6(16.67)$ & $16(21.62)$ & $5(25.00)$ & $44(19.47)$ & $n / s$ & $\mathrm{n} / \mathrm{s}$ & $\mathrm{n} / \mathrm{s}$ & $n / s$ \\
\hline${ }^{*} 0301$ & $20(15.15)$ & $9(25.00)$ & $15(20.27)$ & $0(0.00)$ & 35 (15.49) & $\mathrm{n} . / \mathrm{s}$ & $\mathrm{n} / \mathrm{s}$ & $n / s$ & $\mathrm{n} / \mathrm{a}$ \\
\hline${ }^{*} 0302$ & $9(6.82)$ & $2(5.56)$ & $7(9.46)$ & $1(5.00)$ & $12(5.31)$ & $\mathrm{n} / \mathrm{s}$ & $\mathrm{n} / \mathrm{s}$ & $\mathrm{n} / \mathrm{s}$ & $\mathrm{n} / \mathrm{s}$ \\
\hline \multirow[t]{2}{*}{ *0303 } & $24(18.18)$ & $2(5.56)$ & $5(6.76)$ & $5(25.00)$ & $43(19.03)$ & $n / s$ & $n / s$ & $0.01^{1} ; 0.25$ & $n / s$ \\
\hline & & & & & & & & $(0.07-0.73)$ & \\
\hline${ }^{*} 0401$ & $6(4.55)$ & $2(5.56)$ & $6(8.11)$ & $1(5.00)$ & $7(3.10)$ & $n / s$ & $\mathrm{n} / \mathrm{s}$ & $n / s$ & $n / s$ \\
\hline${ }^{*} 0402$ & $0(0.00)$ & $1(2.78)$ & $1(1.35)$ & $0(0.00)$ & $1(0.44)$ & n.a. & $\mathrm{n} / \mathrm{s}$ & $n / s$ & $\mathrm{n} / \mathrm{a}$ \\
\hline${ }^{*} 0501$ & $1(0.76)$ & $2(5.56)$ & $3(4.05)$ & $0(0.00)$ & $8(3.54)$ & $n / s$ & $\mathrm{n} / \mathrm{s}$ & $\mathrm{n} / \mathrm{s}$ & $\mathrm{n} / \mathrm{a}$ \\
\hline${ }^{*} 0502$ & $5(3.79)$ & $2(5.56)$ & $5(6.76)$ & $0(0.00)$ & $7(3.10)$ & $\mathrm{n} / \mathrm{s}$ & $\mathrm{n} / \mathrm{s}$ & $n / s$ & $\mathrm{n} / \mathrm{a}$ \\
\hline${ }^{*} 0503$ & $4(3.03)$ & $1(2.78)$ & $0(0.00)$ & $2(10.00)$ & $8(3.54)$ & $n / s$ & $\mathrm{n} / \mathrm{s}$ & $\mathrm{n} / \mathrm{a}$ & $n / s$ \\
\hline
\end{tabular}


Table 2 HLA-DQA1, HLA-DQB1, and HLA-DRB1 allele frequencies in PM and DM patients and controls (Continued)

\begin{tabular}{|c|c|c|c|c|c|c|c|c|c|}
\hline${ }^{*} 0601$ & $20(15.15)$ & 7 (19.44) & $11(14.86)$ & $3(15.00)$ & $33(14.60)$ & $\mathrm{n} / \mathrm{s}$ & $n / s$ & $n / s$ & $n / s$ \\
\hline${ }^{*} 0602$ & $4(3.03)$ & $2(5.56)$ & $2(2.70)$ & $2(10.00)$ & $16(7.08)$ & $\mathrm{n} / \mathrm{s}$ & $n / s$ & $n / s$ & $n / s$ \\
\hline *0604 & $5(3.79)$ & $0(0.00)$ & $2(2.70)$ & $0(0.00)$ & $5(2.21)$ & $\mathrm{n} / \mathrm{s}$ & $\mathrm{n} / \mathrm{a}$ & $n / s$ & $\mathrm{n} / \mathrm{a}$ \\
\hline *0608 & $3(2.27)$ & $0(0.00)$ & $1(1.35)$ & $1(5.00)$ & $7(3.10)$ & $\mathrm{n} / \mathrm{s}$ & $\mathrm{n} / \mathrm{a}$ & $n / s$ & $\mathrm{n} / \mathrm{s}$ \\
\hline
\end{tabular}

n/s: not significant; n/a: not applicable; ${ }^{1}$ pcorr greater than 0.05; ILD: interstitial lung disease.

demonstrated that $H L A-D R B 1 * 14$ and $H L A-D R B 1 * 0301$ increase the risk of DM, while $H L A-D R B 1 * 0301$ influences PM susceptibility. Furuya et al. [9,26] found that both $H L A-D R B 1 * 0803$ and HLA-DQA1*0501 provide an increased risk of DM but a reduced risk of PM in a Japanese population. In a study of 25 Korean patients with IIM, Rider et al. [27] reported that $H L A-D R B 1 * 14$ as a protective factor for DM and PM. To date, most studies on the subject have been focused on Western populations. In their studies of $52 \mathrm{DM}$ and PM patients from Northern China, Han et al. reported that $H L A-D R B 1 * 04, H L A-$ $D R B 1 * 07$, and $H L A-D R B 1 * 12$ may render an increased risk of DM [10], while $H L A-D Q B 1 * 0401$ may have an impact on IIM susceptibility [11]. Our data demonstrate that the HLA-DQA1*0104 and HLA-DRB1*07 alleles are likely associated with an increased risk of DM, whereas $H L A$ $D R B 1 * 03$ may provide protection against DM. Although 8.1 $\mathrm{AH}$ is known as a risk factor for IIM among individuals of Northwestern European descent [4,7,28], such an association has not been established in other ethnic groups [25]. DRB1*03-DQA1*05-DQB1*02 is not a major haplotype in our cohort and does not influence DM and PM susceptibility. Our results suggest that the HLA-
$D R B 1 * 07-D Q A 1 * 01-D Q B 1 * 02$ haplotype may be associated with DM and ILD.

It is interesting to note that $H L A-D R B 1 * 07$ influences IIM susceptibility among various ethnic groups. In our study of Han Chinese patients, the $H L A-D R B 1^{*} 07$ allele in the putative haplotype $D R B 1 * 07-D Q A 1 * 01-D Q B 1 * 02$ was found to be a risk factor for $D M$, but the same allele present in the $D R B 1 * 07-D Q A 1 * 02-D Q B 1 * 02$ haplotype was reported to be a protector against IIM in Caucasians and African Americans [4,22,25,28]. These findings imply that HLA-DRB1*07 might have opposite effects on the diseases in different ethnic groups. Similar phenomena have been observed for the effect of $H L A-D Q A 1 * 0501$ on IIM. This allele was reported as a protective factor against IIM in a Japanese population [9] but as a risk factor for IIM among US Caucasians [29]. Although it is unclear what might cause such different effects, possible explanations include referral bias, small sample sizes resulting in nonrepresentative populations, different pathogeneses, various environmental risk triggers around the world, and unidentified genetic loci responsible for disease development.

Furuya et al. [26] reported a positive relationship between $H L A-D R B 1 * 0405$ and anti-aminoacyl-tRNA synthetase

Table 3 Comparisons of frequencies of HLA class II putative haplotypes between DM and PM and controls

\begin{tabular}{|c|c|c|c|c|c|c|c|c|c|}
\hline \multirow{2}{*}{$\begin{array}{c}\text { Haplotypes } \\
\text { DRB1-DQA1-DQB1 }\end{array}$} & \multirow{2}{*}{$\begin{array}{c}\text { DM ( } N=63) \\
n(\%)\end{array}$} & \multirow{2}{*}{$\begin{array}{c}\text { PM }(\mathrm{N}=18) \\
\mathrm{n}(\%)\end{array}$} & \multirow{2}{*}{$\begin{array}{c}\text { Myositis } \\
\text { with ILD } \\
\text { n (\%) N=36 }\end{array}$} & \multirow{2}{*}{$\begin{array}{c}\text { Myositis with } \\
\text { dysphagia } \\
\text { n (\%), N=9 }\end{array}$} & \multirow{2}{*}{$\begin{array}{c}\text { Control }(\mathrm{N}=100) \\
\mathrm{n}(\%)\end{array}$} & \multicolumn{4}{|c|}{$\begin{array}{l}\text { Controls vs. indicated patients } \\
(p ; \text { OR }[95 \% \mathrm{Cl}])\end{array}$} \\
\hline & & & & & & DM & PM & $\begin{array}{l}\text { Myositis } \\
\text { with ILD }\end{array}$ & $\begin{array}{l}\text { Myositis with } \\
\text { dysphagia }\end{array}$ \\
\hline $03-05-02$ & $2(1.59)$ & $2(5.56)$ & $2(2.78)$ & $0(0.00)$ & $11(5.50)$ & $\mathrm{n} / \mathrm{s}$ & $\mathrm{n} / \mathrm{s}$ & $\mathrm{n} / \mathrm{s}$ & $\mathrm{n} / \mathrm{s}$ \\
\hline 04-03-03 & $6(4.36)$ & $1(2.78)$ & $5(6.94)$ & $1(5.56)$ & $9(4.50)$ & $\mathrm{n} / \mathrm{s}$ & $\mathrm{n} / \mathrm{s}$ & $\mathrm{n} / \mathrm{s}$ & $\mathrm{n} / \mathrm{s}$ \\
\hline 04-03-04 & $5(3.97)$ & $2(5.56)$ & $5(6.94)$ & $1(5.56)$ & $6(3.00)$ & $\mathrm{n} / \mathrm{s}$ & $\mathrm{n} / \mathrm{s}$ & $\mathrm{n} / \mathrm{s}$ & $\mathrm{n} / \mathrm{s}$ \\
\hline \multirow[t]{2}{*}{ 07-01-02 } & $12(9.52)$ & $1(2.78)$ & $8(11.11)$ & $2(11.11)$ & $7(3.50)$ & $0.03^{1} ; 2.90$ & $\mathrm{n} / \mathrm{s}$ & $0.02^{1} ; 3.45$ & $\mathrm{n} / \mathrm{s}$ \\
\hline & & & & & & $(1.02-8.93)$ & & $(1.04-11.58)$ & \\
\hline 07-03-02 & $6(4.76)$ & $0(0.00)$ & $3(4.17)$ & $2(11.11)$ & $11(5.50)$ & $\mathrm{n} / \mathrm{s}$ & $\mathrm{n} / \mathrm{s}$ & $\mathrm{n} / \mathrm{s}$ & $\mathrm{n} / \mathrm{s}$ \\
\hline 08-01-06 & $13(10.32)$ & $3(8.33)$ & $6(8.33)$ & $2(11.11)$ & $13(6.50)$ & $\mathrm{n} / \mathrm{s}$ & $\mathrm{n} / \mathrm{s}$ & $\mathrm{n} / \mathrm{s}$ & $\mathrm{n} / \mathrm{s}$ \\
\hline 09-03-03 & 17 (13.49) & $2(5.56)$ & $3(4.17)$ & $3(16.67)$ & $20(10.00)$ & $\mathrm{n} / \mathrm{s}$ & $\mathrm{n} / \mathrm{s}$ & $\mathrm{n} / \mathrm{s}$ & $\mathrm{n} / \mathrm{s}$ \\
\hline $11-05-03$ & $3(2.38)$ & $1(2.78)$ & 1 (1.39) & $0(0.00)$ & $7(3.50)$ & $\mathrm{n} / \mathrm{s}$ & $\mathrm{n} / \mathrm{s}$ & $\mathrm{n} / \mathrm{s}$ & $\mathrm{n} / \mathrm{s}$ \\
\hline $12-01-03$ & $11(8.73)$ & $2(5.56)$ & $8(11.11)$ & $0(0.00)$ & $11(5.50)$ & $\mathrm{n} / \mathrm{s}$ & $\mathrm{n} / \mathrm{s}$ & $\mathrm{n} / \mathrm{s}$ & $\mathrm{n} / \mathrm{s}$ \\
\hline $13-01-06$ & $7(5.56)$ & $0(0.00)$ & $2(2.78)$ & $1(5.56)$ & $7(3.50)$ & $\mathrm{n} / \mathrm{s}$ & $\mathrm{n} / \mathrm{s}$ & $\mathrm{n} / \mathrm{s}$ & $\mathrm{n} / \mathrm{s}$ \\
\hline $14-01-05$ & $2(1.59)$ & $1(2.78)$ & $0(0.00)$ & $2(11.11)$ & $7(3.50)$ & $\mathrm{n} / \mathrm{s}$ & $\mathrm{n} / \mathrm{s}$ & $\mathrm{n} / \mathrm{s}$ & $\mathrm{n} / \mathrm{s}$ \\
\hline $15-01-06$ & $7(5.56)$ & $3(8.33)$ & $3(4.17)$ & $1(5.56)$ & $19(9.50)$ & $\mathrm{n} / \mathrm{s}$ & $\mathrm{n} / \mathrm{s}$ & $\mathrm{n} / \mathrm{s}$ & $\mathrm{n} / \mathrm{s}$ \\
\hline
\end{tabular}


autoantibodies in Japanese IIM patients. In addition, O'Hanlon et al. found that the HLA-DRB1*0302 allele is closely linked to myositis-specific anti-Mi-2 autoantibodies in DM [4]. In our study, the numbers of patients with MSA and MAA were too small to have sufficient statistical power for further analysis of the relationship between $H L A$ alleles and MSA/MAA autoantibodies. It is also noteworthy that a greater frequency of myositis autoantibodies was found among PM patients from our cohort and the cohort reported by Chinoy and colleagues [20]. However, both cohorts were small in size, and in our study we analyzed only a limited number of autoantibodies.

Previous studies suggest that DM and PM may have different pathogeneses. It has been proposed that DM is likely the result of an autoimmune process induced by a humoral response, whereas PM may be caused by a cellmediated autoimmune process [17]. Thus, it is plausible that DM and PM might have distinctive genetic susceptibilities. Further investigation is warranted to better understand the pathogeneses of these two diseases.

Possible explanations for the differences between the results from our study and those from other studies include the fact that the studies were conducted in different geographic locations with various environmental exposures, the heterogeneity in genetic backgrounds among the different ethnic groups and populations, the number of $H L A$ polymorphic alleles analyzed, the different study methodologies used, referral bias, and the age and sex composition of the different study cohorts. The differences in the clinical and immunogenetic features between adult and childhood DM and PM are well documented $[8,31]$.

Our study has some limitations. Although DM and PM are rare conditions and the number of patients in our cohort is the largest compared with similar studies in Chinese patients, it is still a relatively small cohort. It is likely that there are many genes and genetic polymorphisms that may influence DM and PM susceptibility, and we analyzed only a few of them. The data from our study should be validated by further analysis of multiple genes and alleles and their combined impacts on disease susceptibility. Nevertheless, our data shed some light on the genetic susceptibility of adult DM and PM, and may aid in stratifying disease subtypes according to genetic and ethnic backgrounds.

\section{Conclusions}

Our study of adult DM and PM in a Chinese population demonstrated that the putative haplotype $D R B 1 * 07$ $D Q A 1 * 01-D Q B 1 * 02$ and the DRB1*07 and DQA1*0104 alleles are associated with an increased risk of DM, while $D R B 1 * 03$ is associated with a reduced risk of
DM. $D Q B 1 * 0303$ may confer protection against the lung complication, and DRB1*04,DRB1*12, and DRB1*07$D Q A 1 * 01-D Q B 1 * 02$ are associated with an increased risk of developing the lung complication. Furthermore, $D R B 1 * 07$ is associated with an increased risk of developing dysphagia.

\section{Abbreviations}

PM: Polymyositis; DM: Dermatomyositis; HLA: Human leukocyte antigen; IIM: Idiopathic inflammatory myopathies.

\section{Competing interests}

The authors declare that they have no competing interests.

\section{Authors' contributions}

$L B, L L$ and $X G$ conceived the study design and manuscript preparation; $L B$, $L L, X G, L Y, L H, H S$, and $Y Y$ participated in data interpretation; $X G, Y Y, L H, L Y$, $H S$, and GG collected data and conducted experiments and data analysis. All authors read and approved the final manuscript.

\section{Acknowledgements}

We are grateful to the patients and physicians for their participation in the study. This study was supported in part by Shanghai Nature and Sciences Fund (No. 11ZR1404900).

\section{Author details}

${ }^{1}$ The First Department of Health Care, Weifang People's Hospital, Shandong, China. ${ }^{2}$ Departments of Rheumatology and Occupational Medicine, Huashan Hospital of Fudan University, Shanghai, China. ${ }^{3}$ Center for Clinical Molecular Medicine; Ministry of Education Key Laboratory of Child Development and Disorders, Key Laboratory of Pediatrics in Chongqing, Chongqing, China. ${ }^{4}$ Chongqing International Science and Technology Cooperation Center for Child Development and Disorders, Children's Hospital of Chongqing Medical University, Chongqing, China. ${ }^{5}$ Shanghai Children's Hospital, Shanghai Children's Hospital Affiliated to Shanghai Jiao Tong University School of Medicine, Shanghai, China. ${ }^{6}$ Department of Pathology, Geisel School of Medicine at Dartmouth College, Lebanon, New Hampshire, USA.

Received: 18 November 2013 Accepted: 28 May 2014

Published: 4 June 2014

\section{References}

1. Mammen AL: Dermatomyositis and polymyositis: Clinical presentation, autoantibodies, and pathogenesis. Ann N Y Acad Sci 2010, 1184:134-153.

2. Luppi P, Rossiello MR, Faas S, Trucco M: Genetic background and environment contribute synergistically to the onset of autoimmune diseases. J Mol Med (Berl) 1995, 73(8):381-393.

3. Thorsby E, Lie BA: HLA associated genetic predisposition to autoimmune diseases: Genes involved and possible mechanisms. Transpl Immunol 2005, 14(3-4):175-182.

4. O'Hanlon TP, Carrick DM, Targoff IN, Arnett FC, Reveille JD, Carrington M, Gao X, Oddis CV, Morel PA, Malley JD, Malley K, Shamim EA, Rider LG, Chanock SJ, Foster CB, Bunch T, Blackshear PJ, Plotz PH, Love LA, Miller FW: Immunogenetic risk and protective factors for the idiopathic inflammatory myopathies: distinct HLA-A, -B, -CW, -DRB1, and -DQA1 allelic profiles distinguish European American patients with different myositis autoantibodies. Medicine (Baltimore) 2006, 85(2):111-127.

5. Seldin MF, Amos Cl, Ward R, Gregersen PK: The genetics revolution and the assault on rheumatoid arthritis. Arthritis Rheum 1999, 42(6):1071-1079.

6. McLeod R, Buschman E, Arbuckle LD, Skamene E: Immunogenetics in the analysis of resistance to intracellular pathogens. Curr Opin Immunol 1995, 7(4):539-552.

7. Arnett FC, Targoff IN, Mimori T, Goldstein R, Warner NB, Reveille JD: Interrelationship of major histocompatibility complex class II alleles and autoantibodies in four ethnic groups with various forms of myositis. Arthritis Rheum 1996, 39(9):1507-1518.

8. Reed AM, Pachman LM, Hayford J, Ober C: Immunogenetic studies in families of children with juvenile dermatomyositis. J Rheumatol 1998, 25(5):1000-1002 
9. Furuya T, Hakoda M, Higami K, Ueda H, Tsuchiya N, Tokunaga K, Kamatani N, Kashiwazaki S: Association of HLA class I and class II alleles with myositis in Japanese patients. J Rheumatol 1998, 25(6):1109-1114.

10. Han X, Zhai N, Zhang Y, LI J, Liu J, Song F, Cehn H: Association of HLADRB1 alleles and polymyositis/dermatomyositis in northen Chinese. Chin J Microbiol Immunol 2003, 23(3):225-227.

11. Han X, Zhai N, Zhang Q, Li J, Liu J, Du J, Song F: Association of HLA-DQB1 alleles and dermatomyositis/ polymyositis. Chin J Med Genet 2002, 19(4):322-323.

12. Bohan A, Peter JB: Polymyositis and dermatomyositis (second of two parts). N Engl J Med 1975, 292(8):403-407.

13. Bohan A, Peter JB: Polymyositis and dermatomyositis (first of two parts). N Engl J Med 1975, 292(7):344-347.

14. Olerup O, Aldener A, Fogdell A: HLA-DQB1 and -DQA1 typing by PCR amplification with sequence-specific primers (PCR-SSP) in 2 hours. Tissue Antigens 1993, 41(3):119-134.

15. Olerup $\mathrm{O}$, Zetterquist H: HLA-DR typing by PCR amplification with sequence-specific primers (PCR-SSP) in 2 hours: an alternative to serological DR typing in clinical practice including donor-recipient matching in cadaveric transplantation. Tissue Antigens 1992, 39(5):225-235.

16. Stephens M, Smith NJ, Donnelly P: A new statistical method for haplotype reconstruction from population data. Am J Hum Genet 2001, 68(4):978-989.

17. Engel AG, Arahata $\mathrm{K}$, Emslie-Smith A: Immune effector mechanisms in inflammatory myopathies. Res Publ Assoc Res Nerv Ment Dis 1990, 68:141-157.

18. Robinson $A B$, Reed $A M$ : Clinical features, pathogenesis and treatment of juvenile and adult dermatomyositis. Nat Rev Rheumatol 2011, 7(11):664-675.

19. Shamim EA, Rider LG, Pandey JP, O'Hanlon TP, Jara LJ, Samayoa EA, Burgos-Vargas R, Vazquez-Mellado J, Alcocer-Varela J, Salazar-Paramo M, Kutzbach AG, Malley JD, Targoff IN, Garcia-De la Torre I, Miller FW: Differences in idiopathic inflammatory myopathy phenotypes and genotypes between Mesoamerican Mestizos and North American Caucasians: ethnogeographic influences in the genetics and clinical expression of myositis. Arthritis Rheum 2002, 46(7):1885-1893.

20. Chinoy H, Salway F, Fertig N, Oddis CV, Ollier WE, Cooper RG: Clinical, serological and HLA profiles in non-Caucasian UK idiopathic inflammatory myopathy. Rheumatology (Oxford) 2009, 48(5):591-592.

21. Marie I, Hachulla E, Levesque H, Reumont G, Ducrotte P, Cailleux N, Hatron PY, Devulder B, Courtois H: Intravenous immunoglobulins as treatment of life threatening esophageal involvement in polymyositis and dermatomyositis. J Rheumatol 1999, 26(12):2706-2709.

22. O'Hanlon TP, Rider LG, Mamyrova G, Targoff IN, Arnett FC, Reveille JD, Carrington M, Gao X, Oddis CV, Morel PA, Malley JD, Malley K, Shamim EA, Chanock SJ, Foster CB, Bunch T, Reed AM, Love LA, Miller FW: HLA polymorphisms in African Americans with idiopathic inflammatory myopathy: allelic profiles distinguish patients with different clinical phenotypes and myositis autoantibodies. Arthritis Rheum 2006, 54(11):3670-3681.

23. Yu KH, Wu YJ, Kuo CF, See LC, Shen YM, Chang HC, Luo SF, Ho HH, Chen IJ: Survival analysis of patients with dermatomyositis and polymyositis: analysis of 192 Chinese cases. Clin Rheumatol 2011, 30(12):1595-1601.

24. Kuo CF, See LC, Yu KH, Chou IJ, Chang HC, Chiou MJ, Luo SF: Incidence, cancer risk and mortality of dermatomyositis and polymyositis in Taiwan: a nationwide population study. $\mathrm{Br} J$ Dermatol 2011, 165(6):1273-1279.

25. Chinoy H, Lamb JA, Ollier WE, Cooper RG: Recent advances in the immunogenetics of idiopathic inflammatory myopathy. Arthritis Res Ther 2011, 13(3):216

26. Furuya T, Hakoda M, Tsuchiya N, Kotake S, Ichikawa N, Nanke Y, Nakajima A, Takeuchi M, Nishinarita M, Kondo H, Kawasaki A, Kobayashi S, Mimori T, Tokunaga K, Kamatani N: Immunogenetic features in 120 Japanese patients with idiopathic inflammatory myopathy. J Rheumatol 2004, 31(9):1768-1774

27. Rider LG, Shamim E, Okada S, Pandey JP, Targoff IN, O'Hanlon TP, Kim HA, Lim YS, Han H, Song YW, Miller FW: Genetic risk and protective factors for idiopathic inflammatory myopathy in Koreans and American whites: a tale of two loci. Arthritis Rheum 1999, 42(6):1285-1290.

28. Chinoy H, Salway F, Fertig N, Shephard N, Tait BD, Thomson W, Isenberg DA, Oddis CV, Silman AJ, Ollier WE, Cooper RG: In adult onset myositis, the presence of interstitial lung disease and myositis specific/associated antibodies are governed by HLA class II haplotype, rather than by myositis subtype. Arthritis Res Ther 2006, 8(1):R13.

29. Love LA, Leff RL, Fraser DD, Targoff IN, Dalakas M, Plotz PH, Miller FW: A new approach to the classification of idiopathic inflammatory myopathy: myositis-specific autoantibodies define useful homogeneous patient groups. Medicine (Baltimore) 1991, 70(6):360-374

30. Hausmanowa-Petrusewicz I, Kowalska-Oledzka E, Miller FW, JarzabekChorzelska M, Targoff IN, Blaszczyk-Kostanecka M, Jablonska S: Clinical, serologic, and immunogenetic features in Polish patients with idiopathic inflammatory myopathies. Arthritis Rheum 1997, 40(7):1257-1266.

31. Feldman BM, Rider LG, Reed AM, Pachman LM: Juvenile dermatomyositis and other idiopathic inflammatory myopathies of childhood. Lancet 2008 371(9631):2201-2212.

doi:10.1186/1471-5945-14-9

Cite this article as: Gao et al: HLA class II alleles may influence susceptibility to adult dermatomyositis and polymyositis in a Han Chinese population. BMC Dermatology 2014 14:9.

\section{Submit your next manuscript to BioMed Central and take full advantage of:}

- Convenient online submission

- Thorough peer review

- No space constraints or color figure charges

- Immediate publication on acceptance

- Inclusion in PubMed, CAS, Scopus and Google Scholar

- Research which is freely available for redistribution 